\title{
Dementia and Art: Neuronal Intermediate Filament Inclusion Disease and Dissolution of Artistic Creativity
}

\author{
Valmantas Budrys ${ }^{a} \quad$ Kari Skullerud $^{d} \quad$ Donatas Petroska $^{b} \quad$ Jurate Lengveniene ${ }^{c}$ \\ Gintaras Kaubrys ${ }^{\mathrm{a}}$ \\ ${ }^{a}$ Clinics of Neurology and Neurosurgery, Vilnius University Faculty of Medicine, ${ }^{b}$ National Center of Pathology and \\ 'Department of Psychiatry, Vilnius Republical Hospital of Psychiatry, Vilnius, Lithuania; ${ }^{d}$ Department/Institute of \\ Pathology, Rikshospitalet-Radiumhospitalet HF, Oslo, Norway
}

\section{Key Words}

Neuronal intermediate filament inclusion disease •

Frontotemporal dementia · Artistic creativity

\begin{abstract}
The paper presents a new case of neuronal intermediate filament inclusion disease (NIFID), a recently described new variant of early-onset frontotemporal dementia. Documented with repetitive brain images, morphologically proven cases additionally endorse evolving the clinical and pathological phenotype of NIFID. For the first time the paper describes the probable influence of NIFID on the artistic creativity of an accomplished artist showing rapid dissolution of artistic talent.

Copyright $\odot 2007$ S. Karger AG, Basel
\end{abstract}

\section{Introduction}

Artistic talent and creativity is a greatly complex process involving different regions of the brain and, depending on the site and side mostly touched by the disease, could vary from dissolution to emergence of artistic creativity [1-8]. Whether these variations rely exclusively on the affected brain regions or whether the particular his- tomorphological substrate of the different dementia types also plays a role remains unclear. Suggested brain regions mostly involved in visual and other forms of artistic creativity processes by no means need more precise verification, and every documented case of brain disorder of professional or nonprofessional artists provides an opportunity for better understanding of the processes and anatomical zones responsible for specific derangements in artistic perception and creativity.

The paper presents a new case of neuronal intermediate filament inclusion disease (NIFID), a recently described new variant of early onset frontotemporal dementia (FTD), and for the first time describes changes in artistic creativity of an accomplished artist in the setting of NIFID.

\section{Medical History and Clinical Findings}

A 40-year-old right-handed woman was referred to a psychiatrist for assessment of progressive cognitive impairment for the first time in January 2002. The first signs of forgetfulness and some inadequacy in behavior had been noted since the middle of 2000 . Growing inability to cope with usual tasks, apathy, loss of emotions and initiative together with the lack of insight into her condi-

\section{KARGER}

Fax +41613061234 E-Mail karger@karger.ch www.karger.com
(C) 2007 S. Karger AG, Basel

0014-3022/07/0573-0137\$23.50/0

Accessible online at:

www.karger.com/ene
Valmantas Budrys, $\mathrm{MD}, \mathrm{PhD}$

Clinics of Neurology and Neurosurgery, Vilnius University Faculty of Medicine

Vilnius University Santariskiu Klinikos Hospital, Santariskiu 2

LT-08661 Vilnius (Lithuania)

Tel./Fax +370 5236 5220, E-Mail valma@takas.lt 

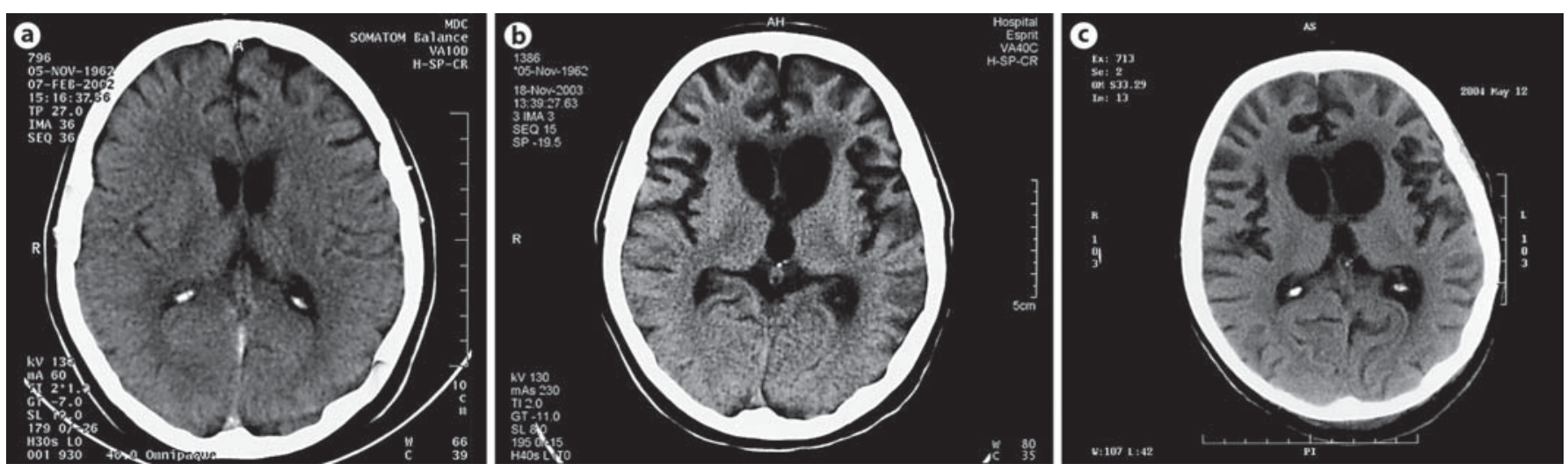

Fig. 1. CT scans showing rapidly progressive atrophy of frontal and temporal lobes and caudate nucleus more pronounced in the left hemisphere. a CT February 2002, minimal atrophy. b CT November 2003, moderate to severe atrophy. c CT May 2004, severe atrophy.

tion had been evident in the middle of 2001. She has no family history of neurological or psychiatric disorders. Due to atypical rapidly progressive cognitive decline she was admitted to an inpatient psychiatric department in March 2002 for more detailed examination and treatment. MMSE at the time of admission was 25/30.

Elements of sensorimotor aphasia, anterograde, retrograde and fixation amnesia, troubles with abstract cognition, echolalia, verbal and writing perseveration, and disorientation in time and space rapidly deteriorated. Together with evident cognitive decline, changes in her personality were also progressively notable. She lost her hygiene habits, neglected almost all commands and stopped eating voluntarily. Episodes of psychomotor agitation and unexplained falls with walking on all fours on the floor were noted. She fully lost the ability to speak and communicate with the people around her at the end of 2003.

Hypomimia, hypophonia, bradykinesia, moderate right arm stiffness with brisk tendon reflexes and elements of extrapyramidal (cogwheel) rigidity were revealed on motor exam at the beginning of 2003. Right leg and left side involvement was minor. There was no muscle atrophy or fasciculations. The sensory exam was hard to interpret due to communication difficulties. No evident tremor, gaze abnormalities or ataxia were noted. Motor function rapidly deteriorated. At the end of 2003 weakness and spasticity of the right arm were particularly marked. Pyramidal and extrapyramidal motor signs were also apparent in the left arm and both legs. In 2004 she lost her mobility and was fully bedridden. Progressive inability to eat, gross loss of weight and rapidly develop- ing multiple bedsores led to the patient's death in 'embryonic pose' in May 2004 with a total clinical duration of the disease of 4 years.

Repeated MRI and CT scans (fig. 1) showed rapidly progressive severe bilateral atrophy (more pronounced on the left) of the frontal and temporal lobes and caudate nucleus, severe enlargement of third and lateral $(\mathrm{L}>\mathrm{R})$ ventricles, hyperintensive zones mostly around the frontal horns of lateral ventricles on $\mathrm{T}_{2}$-weighted imaging and no obvious changes in parietal and occipital lobes, brainstem and cerebellum.

Laboratory testing and EEG were normal.

\section{Morphological Examination}

\section{Gross Pathology}

The weight of the unfixed brain was $1,053 \mathrm{~g}$, and macroscopically severe bilateral atrophy was seen at the frontal and temporal lobes and corpus callosum. No obvious changes were found at the parietal and occipital lobes, thalamus, brainstem and cerebellum. Marked ventricular dilatation was found in the forebrain (fig. 2).

\section{Microscopic Changes}

The brain was sliced as usually into coronal sections. For histological examination, 14 blocks of the brain were taken from: a middle and an upper gyrus of the frontal and temporal lobes, a middle gyrus of the parietal lobe, corpus striatum, thalamic nuclei, hippocampal gyrus, cerebellum (folia and nucleus dentatus), pons, medulla oblongata, spinal brain (cerebral part) and cingulate gy- 

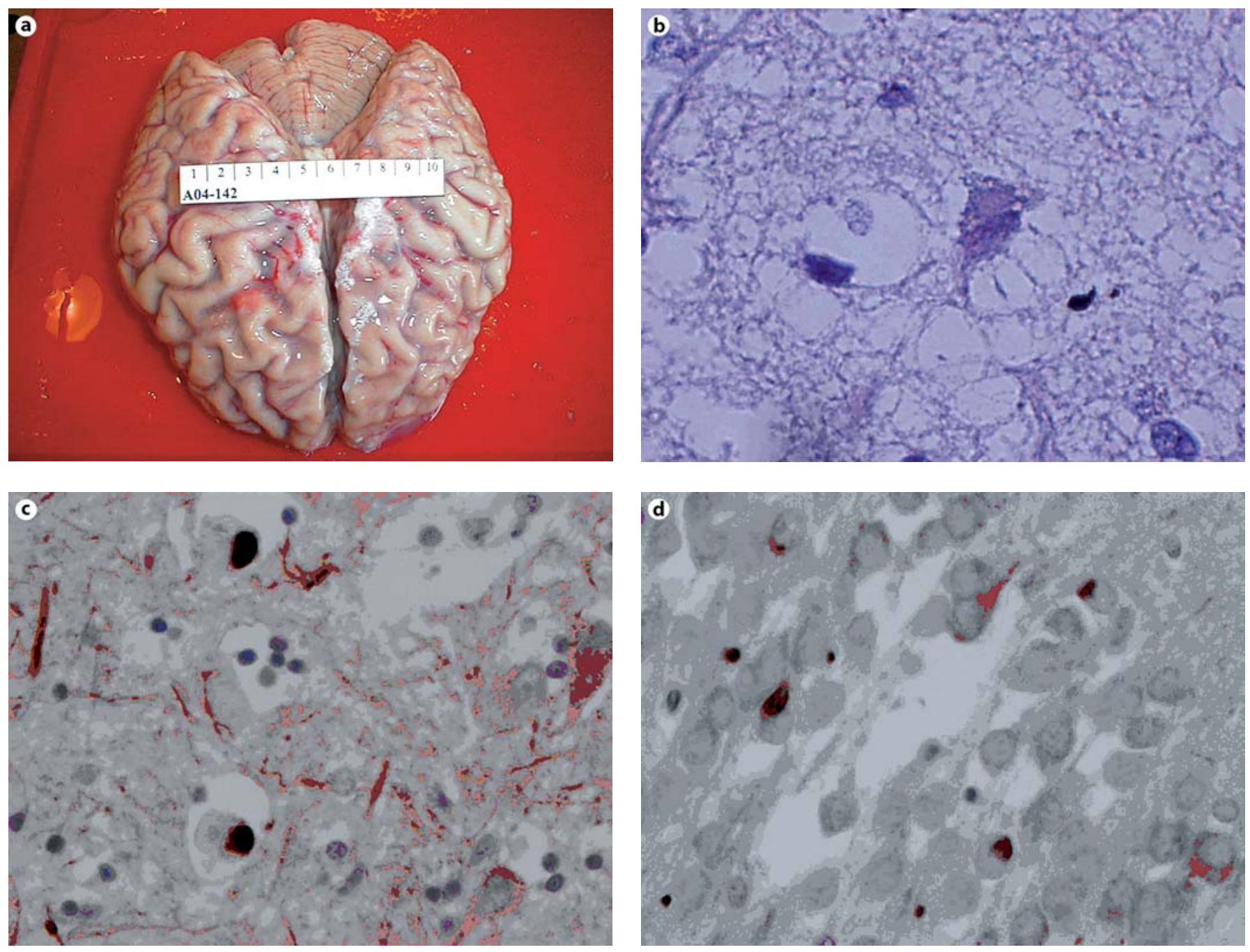

Fig. 2. Morphology of the brain. a Severe cerebral atrophy of frontal and temporal lobes. b Inclusion body in cytoplasm of neuron with adjacent spongiform changes. HE. $\times 400$. c Intracytoplasmic inclusion in cortical neurons of frontal lobe. $\alpha$-Internexin. $\times 400$. $\mathbf{d}$ Intracytoplasmic inclusion in neurons of granular layer in hippoccampus. $\alpha$-Internexin. $\times 400$.

rus with a corpus callosum. In routine histological sections moderate spongiform changes were seen in the superficial layers of the frontal and temporal cortex with moderate loss of neurons and slightly pronounced reactive gliosis. Severe neuronal loss and reactive gliosis were present in the corpus striatum, some parts of the thalamus and the pyramidal layer of the hippocampi. Axonal swellings (wallerian degeneration) were found in the corticospinal tracts. Cerebellum revealed Purkinje cell loss with astrocytosis and few necrotic Purkinje cells with signs of neurophagia.

Dementia and Art
Weakly eosinophilic spherical inclusions with a basophilic membrane in a cytoplasm of neurons were detected on HE-stained sections. These inclusion bodies could be named as 'Pick-body-like inclusions' due to a morphological identity with bodies presented in cases of Pick's disease. These inclusions were the most numerous and widespread in remaining neurons of the most severely degenerated areas of the corpus striatum, thalamus and pyramidal layer of the hippocampi (granular cell layer, pyramidal neurons and cortical neurons adjacent to gliosis). Scattered neuronal inclusions were observed in the tegmental and pontine nuclei. No neuronal inclusions

Eur Neurol 2007;57:137-144 
were found in the cerebellum, suggesting the changes to be terminal hypoxic in this location.

Histochemical methods revealed very weak Bodian silver staining (-/+) and negative Gallyas silver staining $(-)$ of the inclusion bodies. Immunohistochemically all neuronal inclusions were weakly positive for neuronal filament (+), ubiquitin (+/-) and without reaction to $\alpha$ synuclein (-). No signs of neuronal fibrillary tangles, senile plaques or glial cytoplasmic inclusions were found. All these morphological data combined with immunohistochemical, histochemical and clinical data excluded all the most frequent neurodegenerative disorders, such as tauopathies, $\alpha$-synucleinopathies, prion diseases and neurofilamentopathies. Finally, intensive positive $\alpha$-internexin $(+++)$ staining of inclusion bodies led to the final diagnosis of NIFID.

\section{Art History}

V.V. was a professional artist from an artist family. After graduating from the Lithuanian Art Academy in 1988 she produced paintings, engravings, poetry and performances. In 1995 she established and was an art director of the modern environmental puppet theater. A few performances were created and successfully performed in Lithuania and abroad. Progressive lack of self-criticism, growing inability to cope with usual artistic tasks and evident emotional dimness were firstly noted by her fellows during the preparation of the last performance in 2001.

In 2002 (being already ill) she composed and issued her first and last poem book with her personal engravings symbolically named Departures (Išvykèliai). As all poems had been written before the clinical manifestation of the disease, only some obviously artistically weak poems in the book could be attributed to the lack of self-criticism related to the progression of the disease, as well as to the significant fact that she had not written any more poems since the end of 2000. In January 2002 during the vernissage of her 1-person exhibition in an art gallery, she, very unexpectedly to all spectators, was unable to pronounce any understandable opening speech and only muttered a few intimate phrases not related to the exhibition. Substantial stylistic changes and professional decline of her paintings were noted for the first time during this exhibition.

V.V.'s purely abstract style (fig. 3) changed to symbolic concreteness uncharacteristic of professional artists. Elements of aggressiveness and disquietude appeared in her works (fig. 4). Some of her last paintings and many of the drawings created already being moderately demented ap- parently spread inner fear and a silent cry for help (fig. 5, 6). Interestingly, these expressions resemble (and evolved from) the dance - an important component of V.V.'s performances and the favorite subject of her graphic art. Her last drawings could be asserted as primitively realistic.

V.V.'s soft and elegant colors changed to sharp and dry, an unusual red color (color of fear and anxiety?) appeared in her works and the whole color spectrum shifted from her favorite blue-green to predominantly pure unmixed 'primary' colors - red, blue and yellow. Noteworthily, copying (fig. 7) was almost not disturbed, but even then the original drawings became very primitive; highly characteristic series of drawings with color pencils on long narrow paper strips with almost the same repetitious primitive figures - drawing perseveration (fig. 6). We also present two pages of the sheet of paper (created as a letter) with her very last primitive drawing and repetitive phrases with multiple grammar mistakes (fig. 8), which resembles the 'amnestic writing disorder' of Auguste D., the first and foremost Alzheimer's patient [9].

\section{Discussion}

Recently described NIFID is a neuropathologically distinct, clinically heterogeneous variant of FTD $[10,11]$. Very few verified NIFID cases are known from the literature till now and many questions concerning disease ethiopathogenesis, clinical findings and management yet wait to be disclosed. Every new reported case validates already known or adds new data to the evolving clinical phenotype of this novel form of FTD. The clinical features of NIFID depend on the anatomical structures affected as well as the severity of the lesions with the prominent phenotype of frontotemporal cortical dysfunction $[10,12-$ 14]. Early-onset atypical rapidly progressive dementia, decline in social and personal conduct, as well as language and memory difficulty are the most frequent and prominent cognitive features $[10,11,13,14]$. All of them were apparent in our case. Pyramidal and extrapyramidal signs are common motor features and were detected in most NIFID cases presented in the literature $[10,11,13,14]$. Weakness and spasticity with brisk tendon reflexes together with extrapyramidal (cogwheel) rigidity without evident tremor were the clinical motor features of our patient, and this additionally strengthens the combined (pyramidal and extrapyramidal) motor phenotype characteristic of NIFID. In the case presented here there were no signs of supranuclear ophthalmoplegia, buccofacial apraxia or limb dystonia detected in some other cases. 


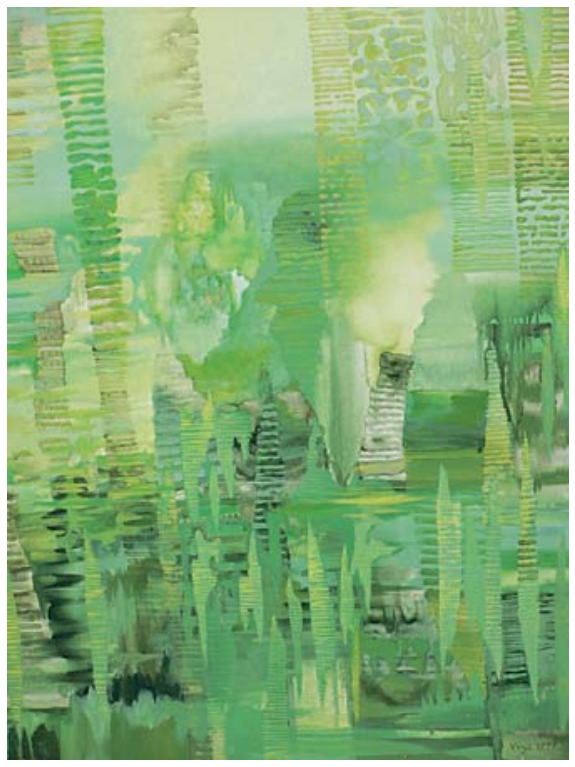

Fig. 3. Typical abstract V.V. painting created 2 years before the disease.

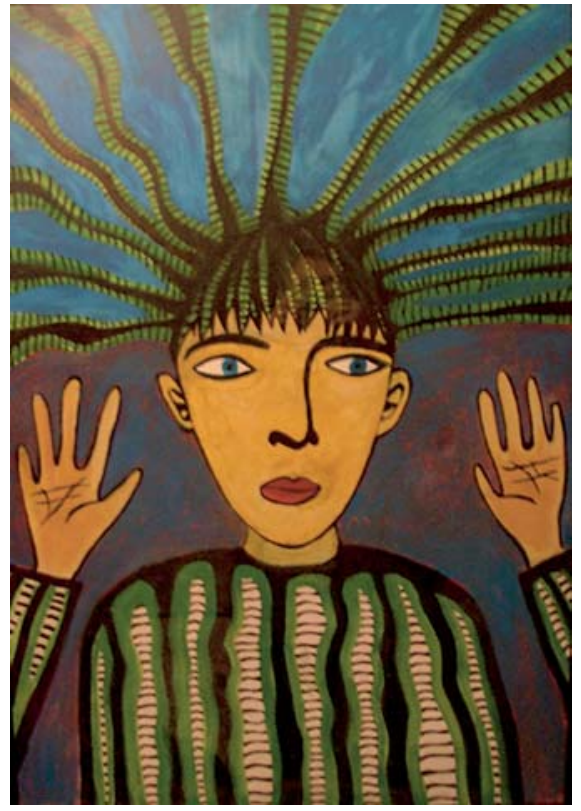

Fig. 5. Some of V.V.'s last paintings created already being moderately demented apparently spread inner fear and a silent cry for help.

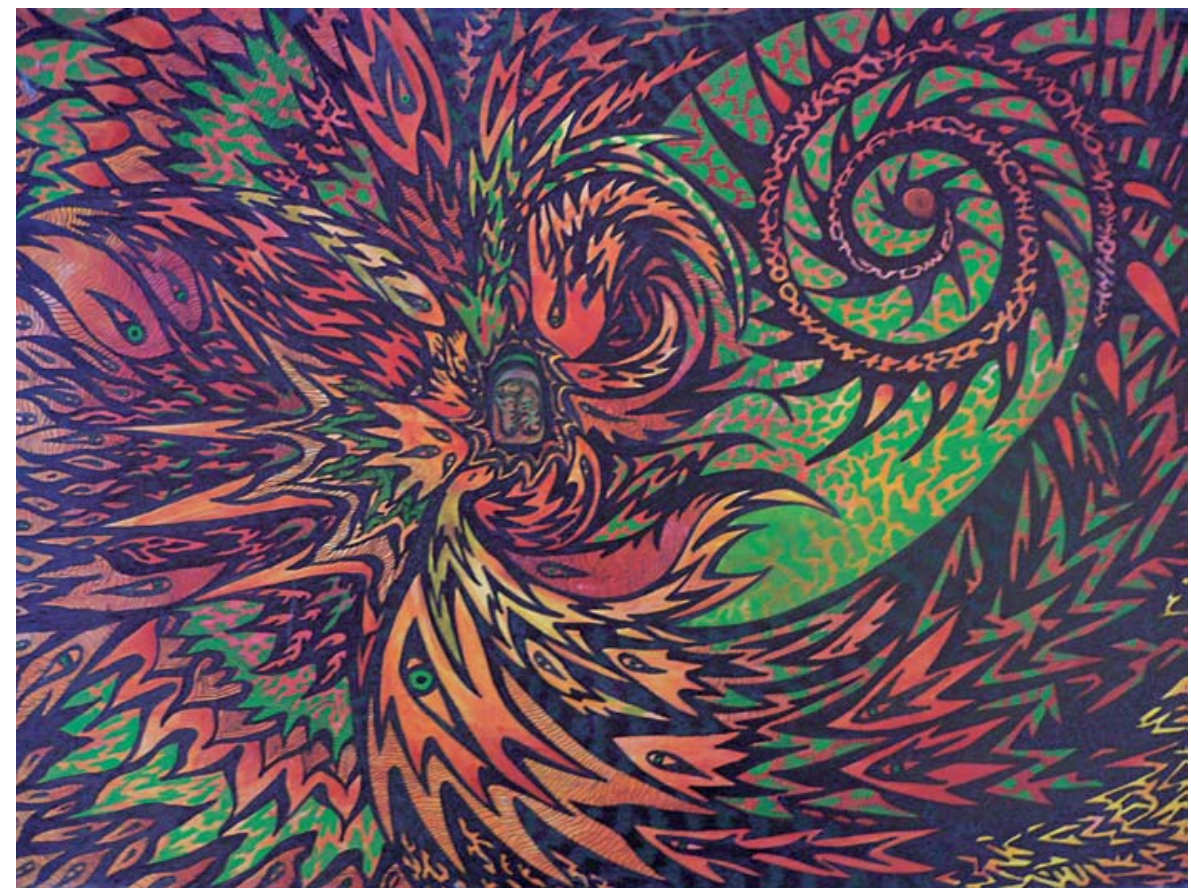

Fig. 4. Elements of anxiety and aggressiveness could be noted in V.V.'s works since the early course of NIFID.
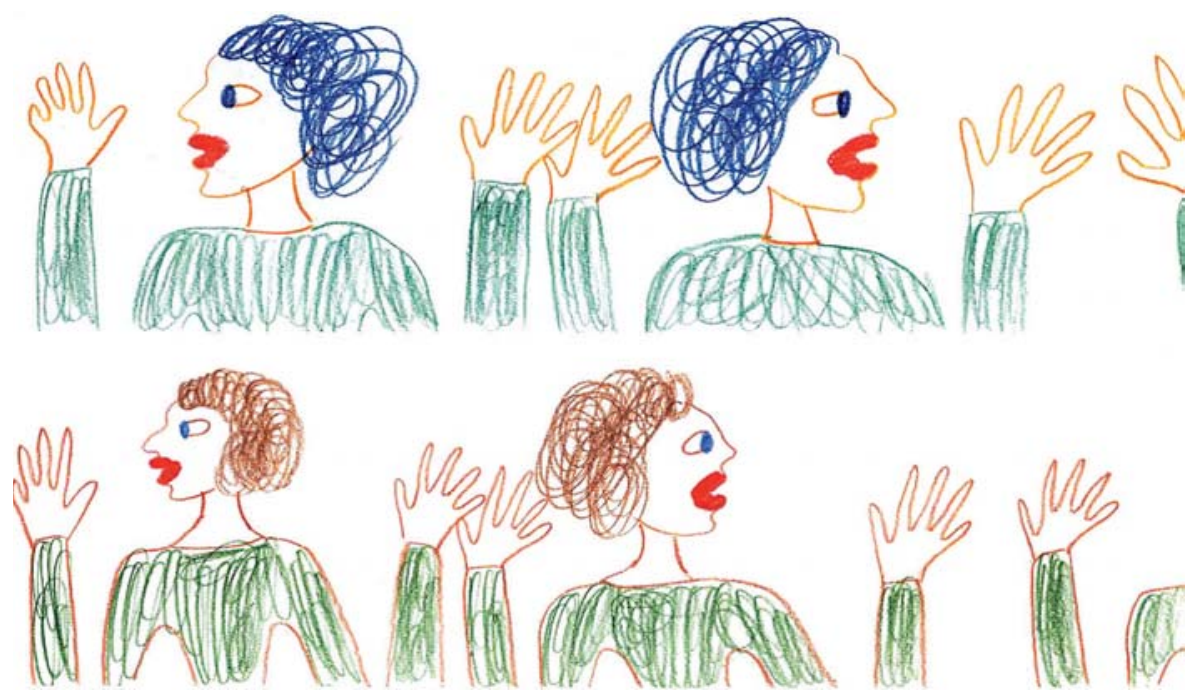

Fig. 6. Two fragments of series of drawings with color pencils on long narrow paper strips with almost the same repetitious primitive figures - drawing perseveration. 


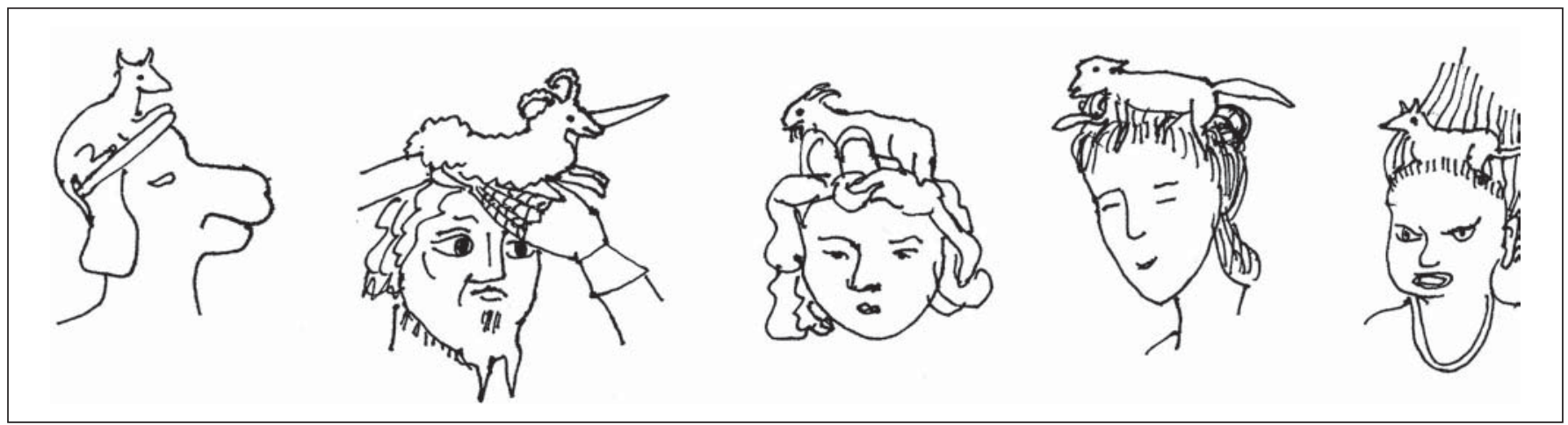

Fig. 7. Copy of pictures from the art book created in the advanced stage of NIFID argues that copying was almost not disturbed, but even then the original drawings became very primitive.
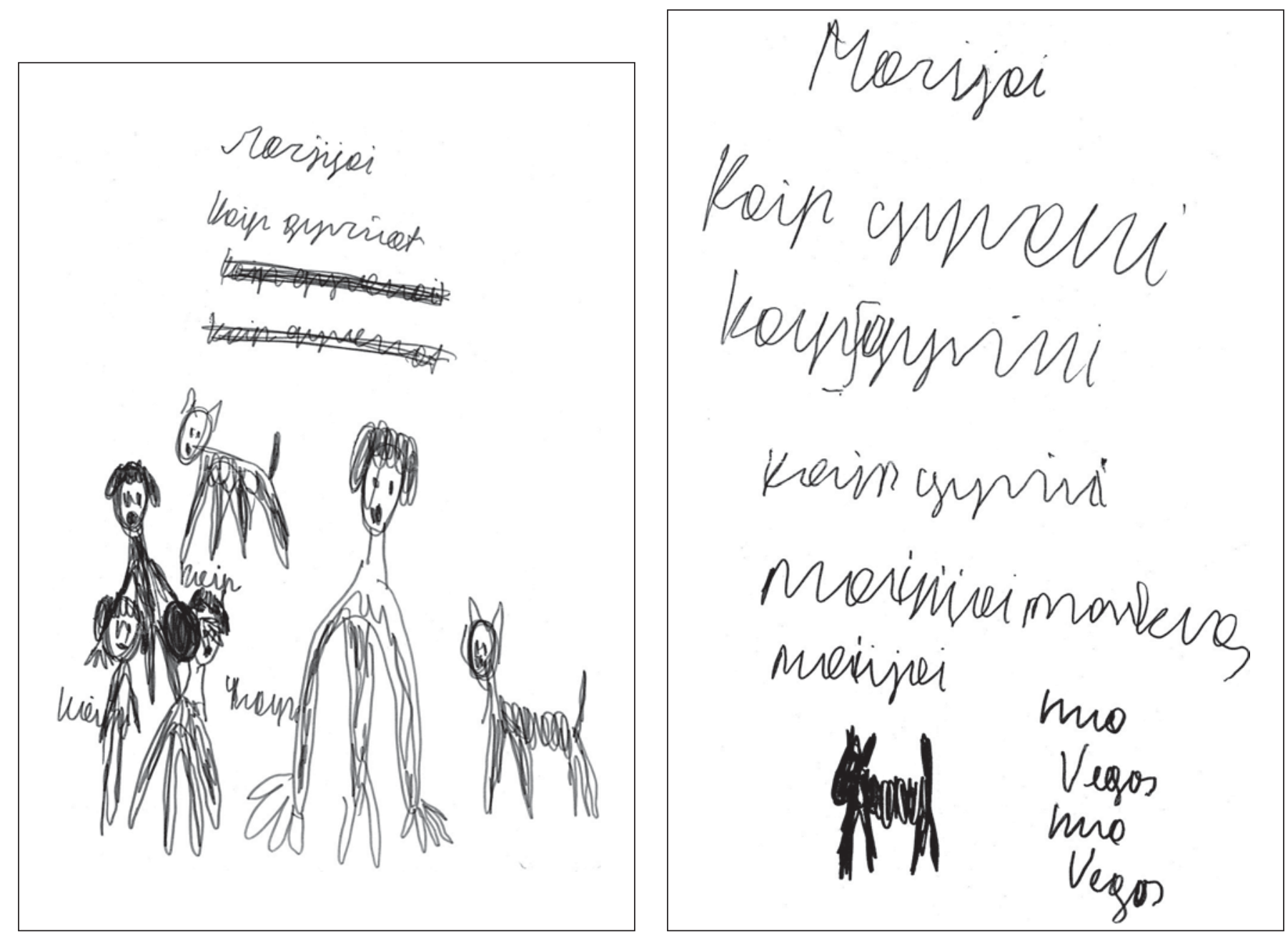

Fig. 8. Two pages of the sheet of paper with V.V.'s very last primitive drawing and repetitive phrases with multiple grammar mistakes. 
With only one exception of parkinsonism followed by dementia [11], none of the other described cases, including the case presented here, had a family history of neuropsychiatric disease. Nevertheless, unusually early onset of dementia could be suggestive of recessive genetic disorder [10].

Structural brain imaging showed atrophy of the frontal and temporal lobes and caudate nucleus in most, albeit not all previously reported cases. Neuropathologic examination revealed marked atrophy of the frontal lobe in all reported cases, whereas some cases reported an unremarkable temporal lobe $[13,14]$, suggesting variability in the pathological phenotype of NIFID. Our case revealed rapidly progressive atrophic changes of both frontal and temporal regions together with marked atrophy of the caudate nucleus clearly evident on repetitive brain images and later confirmed macroscopically. No obvious changes in parietal and occipital lobes, thalamus, brainstem and cerebellum were noted.

Due to clinical overlap between FTDs, precise differential diagnosis entirely depends on careful autopsy examination. NIFID can be distinguished neuropathologically from the other FTD subtypes by the hallmark lesion: unique intermediate filament inclusions most robustly detected by $\alpha$-internexin, which is a sign of such inclusions $[10,13]$. Clearly evident $\alpha$-internexin intracytoplasmic inclusions in cortical neurons of the frontal lobe and neurons of the granular layer in the hippoccampus of the presented case verifiy the NIFID diagnosis.

Taken together our case presents all most characteristic features of NIFID cases previously reported in the literature and additionally endorses the evolving typical clinical and pathological phenotype of NIFID.

Dementia differently affects creative processes. Several articles describing the influence of progressive dementia on artistic talent and creativity present results from deterioration $[2,4,5]$ to enhancement $[1,6-8]$ of artistic creativity and thereby foreground the polygenicity of dementia as well as the complexity of creativity processes. A degenerative process, depending on its nature, could hardly damage particular segments of the brain leaving others almost unaffected. This is the main though not only factor contributing to different influences on creativity and artistic ability in different types of degenerative dementia. According to Mendez [15], FTD may be a disorder that can affect the brain in just the right ways to illustrate mechanisms of artistic expression.

The presented case deals with the three different sorts of artistic expression in the setting of a new variant of FTD: visual art, performance and poetry. Poetry as a form of artistic expression was affected first, confirming the postulated hypothesis that the left anterior temporal lobe damage mainly affects verbal abilities: word naming, comprehension and semantics [15-17]. Growing inability to cope with usual artistic tasks due to progressive lack of self-criticism and motivation, emotional dimness, difficulties in recognizing the characters and inability to clearly understand the text of the story soon interrupted V.V.'s performance creativity. Although V.V. preserved her ability to paint and draw for a longer time, stylistic changes in her works appeared early in the disease course and the professional quality of the works rapidly deteriorated. A few characteristic changes of V.V.'s art probably related to NIFID could be noticed in her paintings and drawings created during the course of disease: turn from abstract to symbolic concreteness and 'return' to the child's 'realistic' primitivism at the advanced stage of the disease (contrary to the documented cases of the artists with Alzheimer's disease who mostly turned from realistic to abstract style in the course of disease $[15,18,19])$; shift of color spectrum to predominantly 'primary' colors (the feature also noted in the works of the other artists developing both FTD and Alzheimer's disease [5, 8, 20, $21,22]$ ); appearance of aggressiveness and disquietude; drawing perseveration (also noted in the reported cases of FTD [1, 8]); visual expression of inner fear and silent cry for help (one could note a similar expression of cry and fear in the works of the artists with different forms of dementia $[1,18,23])$.

In summary, the presented NIFID case shows early and rapid decline of both verbal and visual artistic creativity, which mainly matches the course of the neuroanatomical changes. The authors, of course, clearly understand the difficulty of drawing definite conclusions on the basis of a unique report. More cases with specific neuropsychological, cognitive and behavioral data are necessary to correlate anatomic-clinical changes and artistic creativity in NIFID more precisely. This article is only the first attempt to describe the convergence of these two.

\section{Acknowledgments}

The article is devoted to the memory of V.V.

The authors thank Mrs. Ula Vaiciunaite for the possibility to familiarize with the diary and works of V.V., essential comments on them and kind permission to reproduce the works. 


\section{References}

1 Chang Mell J, Howard SM, Miler BL: Art and the brain: the influence of frontotemporal dementia on an accomplished artist. Neurology 2003;60:1707-1710.

2 Cummings JL, Zarit JM: Probable Alzheimer's disease in an artist. JAMA 1987;258: 2731-2734.

-3 Fornazzari LR: Preserved painting creativity in an artist with Alzheimer's disease. Eur J Neurol 2005; 12:419-424.

4 Kleiner-Fisman G, Black SE, Lang AE: Neurodegenerative disease and the evolution of art: the effects of presumed corticobasal degeneration in a professional artist. Mov Disord 2002;18:294-302.

5 Maurer K, Prvulovic D: Paintings of an artist with Alzheimer's disease: visuoconstructural deficits during dementia. J Neural Transm 2004;111:235-245.

-6 Miller BL, Ponton M, Benson DF, Cummings JL, Mena I: Enhanced artistic creativity with temporal lobe degeneration. Lancet 1996; 348:1744-1748.

7 Miller BL, Cummings J, Mishkin F, Boone K, Prince F, Ponton M, Cotman C: Emergence of artistic talent in frontotemporal dementia. Neurology 1998;51:978-982.

$\checkmark 8$ Miller BL, Hou CE: Portraits of artists: emergence of visual creativity in dementia. Arch Neurol 2004;61:842-844.

9 Maurer K, Volk S, Gerbaldo H: Auguste D and Alzheimer's disease. Lancet 1997;349: 1546-1549.
10 Cairns NJ, Grossman M, Arnold SE, Burn DJ, Jaros E, Perry RH, Duyckaerts C, Stankoff B, Pillon B, Skullerud K, Cruz-Sanchez FF, Bigio EH, Mackenzie IRA, Gearing M, Juncos JL, Glass JD, Yokoo H, Nakazato I, Mosaheb S, Thorpe JR, Uryu K, Lee VMY, Trojanovski JQ: Clinical and neuropathologic variation in neuronal intermediate filament inclusion disease. Neurology 2004;63:13761384.

11 Josephs KA, Holton JL, Rossor MN, Braengaard $\mathrm{H}$, Ozawa T, Fox NC, Petersen RC, Pearl GS, Ganguly M, Rosa P, Laursen H, Parisi JE, Waldemar G, Quinn NP, Dickson DW, Revesz T: Neurofilament inclusion body disease: a new proteinopathy? Brain 2003;126:2291-2303.

12 DeKosky ST, Ikonomovic MD: NIFID: a new molecular pathology with a frontotemporal dementia phenotype. Neurology 2004;63: 1348-1349.

13 Josephs KA, Uchikado H, McComb RD, Bashir R, Wszolek Z, Swanson J, Matsumoto J, Shaw G, Dickson DW: Extending the clinical spectrum of neurofilament inclusion disease. Acta Neuropathol 2005;109:427432.

14 Mackenzie IRA, Feldman H: Neurofilament inclusion body disease with early onset frontotemporal dementia and primary lateral sclerosis. Clin Neuropathol 2004;23:183193.
15 Mendez MF: Dementia as a window to the neurology of art. Med Hypotheses 2004;63: $1-7$.

16 Gordon N: Unexpected development of artistic talents. Postgrad Med J 2005;81:753755.

17 Miller BL, Seeley WW, Mychack P, Rosen HL, Mena I, Boone K: Neuroanatomy of the self: evidence from patients with frontotemporal dementia. Neurology 2001;57:817821.

18 Crutch SJ, Isaacs R, Rossor MN: Some workmen can blame their tools: artistic change in an individual with Alzheimer's disease. Lancet 2001;357:2129-2133.

19 Maurer K, Frölich L: Paintings of an artist with progressive Alzheimer's disease. Alzheimers Insights 2005;6:11.

20 Bogousslavsky J: Artistic creativity, style and brain disorders. Eur Neurol 2005;54:103111.

21 Espinel CH: De Kooning's late colours and forms: dementia, creativity, and the healing power of art. Lancet 1996;347:1096-1098.

22 Wijk H, Berg S, Sivik L, Steen B: Colour discrimination, colour naming and colour preferences among individuals with Alzheimer's disease. Int J Geriatr Psychiatry 1999;14:1000-1005.

23 Sahlas DJ: Dementia with Lewy bodies and the neurobehavioral decline of Mervyn Peake. Arch Neurol 2003;60:889-892. 